\title{
Covid-19 Pandemic and its Politico-Economic Implications: A Study of Pakistan
}

\author{
Misbah Shaheen ${ }^{1 *}$, Uzma Siraj ${ }^{2}$ and Muhammad Nawaz Bhatti ${ }^{1}$ \\ 1. Department of Politics \& International Relations, University of Sargodha, Pakistan. \\ 2. Department of Pakistan Studies, Federal Urdu University, Islamabad, Pakistan.
}

\begin{abstract}
Pakistan is one among the countries terribly affected by the novel contagious disease named "COVID-19". The severe economic shortfall caused by the pandemic is likely to worsen the already frangible situation of political stability. A country of over 220 million people with a fragile democracy, brittle health system, and the sinking economy is vulnerable to the drastic politico-economic implications of COVID-19. Hence, the present study aims to analyze the politico-economic implications of this on-going pandemic for Pakistan. Mixed-method research design has been employed to investigate the research question, as the only quantitative or qualitative analysis was not much appropriate to develop a better understanding of the problem investigated in the study. The simultaneous application of both the numerical and opinion-based data provided a comprehensive framework to reach logical findings. The study concludes that the inadequate health facilities and less coordinated response, along with a substantial decline in GDP, will make the post-pandemic scenario more challenging and cumbersome. The study suggests an integrated and coordinated approach to cope with this deadly phenomenon presently and to minimize the unfavourable implications in the future.
\end{abstract}

Keywords: COVID-19, Pandemic, Crisis Management, Political Impact of COVID-19, Economic Impact of COVID-19.

\section{Introduction}

The term 'pandemic' refers to an infectious and contagious disease that flares up and spreads rampantly. That may affect a vast number of humans very quickly. Its history is as old as humans are, and even this technological modern era is not immune to it. Such outbreaks are approximately constant, though not every epidemic catches up a pandemic level. History is the bystander of various such pandemics, which caused a massive level of human loss viz. Spanish Flu (out broke in 1918-19 causing 40-50 million deaths), Hong Kong Flu (out broke in 196870, resulting in 01 million fatalities), Asian Flu (out broken in 1957-58 and caused 1.1 million death toll) (Wua \& Chan, 2020; Bedford et al., 2020). They not only caused extensive human loss but also badly devastated the economies of the affected countries. The published literature explores that the plausibility of pandemics relatively has been heightened over the past century due to widespread global travel, urbanization, and more substantial exploitation of the natural environment (Samal, 2014). The Earth planet suffered another horrible outbreak of such a pandemic on December 31, 2019, when China reported World Health Organization (WHO) country office about the outbreak of mysterious pneumonia characterized by high fever, dry 
cough, very sore throat, tiresome, and periodic gastrointestinal symptoms took place in a seafood market, the Huanan Seafood Wholesale Market, in Wuhan, Hubei, China. Though the affected market was shut down immediately; however, in the ensuing month of January, thousands of people became the target of this mysterious contagious disease (Sareen, 2020).

Furthermore, in a short time, on February 6, 2020, WHO involving at least 25 countries (WHO, 2020), globally documented a significant number of 28,276 confirmed cases and 565 deaths. In a couple of months, its rampant spread had reached in every nook and corner of the world with a confirmed 8,060,496 affected cases and 437,054 death tolls (Worldometer, 2020). Presently it has been termed COVID-19, an abridged form of "coronavirus disease of 2019." and was declared a pandemic in March 2020 by WHO as no one living on this planet is safe and immune from it. As soon, it was explored that it is an infectious disease spreading from one person to the other. Various precautionary measures were suggested by the official authorities to counter its spreading speed such as; awareness campaign to often wash hands for at least twenty seconds, usage of hand sanitizer, social distancing and limited mobility, partial closure of public places such as parks, restaurants, shopping centres, marriage halls, schools, colleges, and universities, etc. However, when the spreading pace of the virus became multiplied, the majority of the countries' heads imposed either partial or complete lockdowns that led to dividing the political leadership of the respective countries on the stance that either the complete lockdown and long term is required or the partial lockdown only for hotspots would fulfill the purpose. Besides, the decision to put the lockdown may adversely affect the economy and particularly the poor segment of the society, so how to deal with this painful and complicated paradox became a key challenge for the countries.

As mentioned above that every square inch of the world has been affected severely by the COVID-19 virus, Pakistan could not remain immune to it, and on February 26, 2020, at Karachi (Sindh), the first case was reported; 22-years old Yahya Jaffery (first patient) came back to the country from Iran (Hussain, 2020). Up to the mid of March, the number increased up to 28 cases across the country. Although Pakistan was introduced to this novel virus through travellers, commuters, and pilgrims coming back from countries like Iran, the Middle East, and Europe. Pakistan, hitherto, has plunged into more than one hundred thousand cases while the death toll has reached up to 2700 , which is forecasted to be multiplied in the coming weeks. To avoid such massive human loss, Pakistan's Prime Minister announced a partial lockdown at the end of March 2020 that remained continued till the first week of May 2020. As the only strategy to slow down the rampant spread of the virus is successful through maintaining proper social distancing, that can only be made fruitful by imposing lockdown in the cities as well as in villages. If a lockdown is not imposed, there is a high risk of massive infection rates, which can overwhelm the already fragile health infrastructure, resulting in a substantial human loss.

Nevertheless, on the other side, lockdowns tend to throttle the economy in multiple ways. The economic fall-out may paralyze the already crippled economy, and it threatens the livelihood of those living below the poverty line. It is a split decision and needs a delicate balance of controlling the virus while not destroying the economy in the process and to protect the poor segment from starvation. Thence it is pertinent to scourge the facets of the negative impact on the economy from the COVID-19. The present article seeks to analyze the potential impact of this pandemic on the political and economic life of the world generally and to investigate its effects on the political economy of Pakistan more directly as no walk of life may escape, so the sector of social life is not immune to its crippling effects. Its spread in the entire world has unveiled the inefficiency of the health system even in the developed world. In such 
circumstances, the political and economic implications seem to be disastrous. The situation is even worse in developing countries like Pakistan, where inadequate and insufficient health facilities, weak health infrastructure, and governments' inability to counter such crisis raise many questions.

Thus, the present study is a significant contribution towards the available literature on this scholarship because it not only highlights the weakness of the health sector but analyses the political-economic implications of COVID-19 for Pakistan. This study presents an in-depth examination of Pakistan's current health infrastructure. It highlights the inadequacies in medical facilities and evaluates the government's performance in this crisis. The study uses statistical data of available health facilities to compare it with the population to find out its insufficiency for a population of 220 million. Secondly, It looks at the economic implications of COVID-19 in a situation where the government had to divert the resources from other sectors to meet this suddenly arrived deadly phenomenon. Moreover, the sudden halt of economic activity worldwide has severely hampered Pakistan's struggling export sector. Furthermore, the response of political leadership is critical in such a crisis. Pakistan's weak democracy, divided political leadership, lack of political willingness for a coordinated response from the government benches and the opposition has made the situation more challenging. This study aims to investigate what kind of implications Pakistan is going to face as a result of the pandemic at social, economic, and political levels.

The research paper has been organized into four sections. Its opening section briefly explores the on-going scenario in the context of COVID-19 and proceeds explaining the complex correlation between the pandemic and the possible measures taken to alleviate it. The next section describes the data and methods employed to get the relevant information and to analyze it accordingly that follows the discussion revolves around the possible impacts of COVID-19 on the economic growth and politics of Pakistan. The last section summarises the study coherently by concluding that Pakistan would have to face severe economic shortfall as nearly $2.4 \%$ annual GDP will be lost due to higher unemployment rate, meagre tax collection, massive reduction in foreign remittances from Europe and Middle Eastern countries (Ahmad, Haroon, Baig, \& Hui, 2020). Besides this, the incumbent political leadership may lose electoral support in the next polls due to the unsatisfactory measures taken to cope with the pandemic.

\section{Literature Review}

Human suffering in all aspects is the ultimate consequence of infectious diseases. They not only cause horrendous economic damages, but political spheres are not immune to this. The death ratio of COVID-19 has surpassed the number of fatalities in armed conflicts in recent years (Patrick, 2011). The study of infectious diseases and their impacts on states has been an essential topic of study. Many researchers have evaluated the impacts of epidemics on state security, economic development, even on the fall of empires. Contemporary literature discusses this phenomenon in the context of Ebola, Sars, Swine flu, Avion Flu, and other diseases. However, the outbreak of COVID-19 is more contagious in all of its dimensions. Once the pandemic is over, the real consequences will be calculated. However, it is manifested that COVID-19 will be having unpredictable implications for the global political economy in general and for developing states in particular.

Armelagos et al., (2005) conducted a comprehensive study in evaluating the different phases of the history of epidemics how their fatal consequences are reduced in intensity due to 
improving health conditions. They evaluated almost 10,000 years of history of epidemics dividing it into three phases. The third phase, according to George and Peter, is more devastating when such diseases are becoming novel and resistant to the multi antibiotic. They are more widespread and pose a severe threat to the ability of weak states in combating them. Assessing their economic impact is an especially critical domain for developing states like Pakistan. Malani and Laxminarayan, (2011) have given an extensive account of the economic impact of infectious diseases on developing states. They focus on labour productivity and investment behaviour in case of epidemics and also discuss the ability of risk-taking while making a crucial decision that might impact the economy. Organizational research also through the light at the different economic aspects of pandemics. A study conducted by IMF in 2018 titled "Epidemics and Economic" gives a comprehensive account of social distancing, resulting in both social and economic losses of effected and their caretakers. By using the examples of different epidemic outbreaks in Europe and Africa, it argues that such scenarios might complicate the economic outlooks of states for a long time to come. Their ability to maintain trade relations, international connectivity gets severely influenced. It also destroys the burdened health sector of developing nations with insufficient budgetary allocations to the health sector (Bloom \& Cadarette, 2019.

Shafi et al., (2020) investigated the impact of COVID-19 on small, micro, and medium-sized enterprises currently working in Pakistan. A sample of one hundred and eighty-four MSMEs were drawn, and their response was collected through a close-ended online questionnaire. The findings of the study revealed that the majority of such companies is facing serious problems such as; low demand, low profit, and disrupted supply chain. (Noreen et al., 2020) assessed the prevailing situation of Pakistan's preparedness during the pandemic. Their study highlighted that due to low literacy rate and unawareness, masses were not considering this infectious disease fatal. Therefore, they were not ready to observe the standard operating procedures directed by official authorities. The study recommended full coordination between the federation and federating units, responsible role of media, and significant increment in health budget. Ahmad et al., (2020). examined the impact of coronavirus on the economy of the world. Their study projected that China's economic growth would fall by 5.6 percent, France, Italy, German, UK and Japan's public sector funding program would be decreased 10 percent of their annual GDP. The study insisted on local, regional, and international cooperation to stop the rampant spread of this deadly disease Janjua et al., (2020) analyzed the post-COVID-19 situation and Pakistan's strategy to deal with this pandemic. Their study explored that the countries (Singapore, Hong Kong, and South Korea) ranked at the top; they managed this pandemic crisis effectively due to having the best healthcare systems. In comparison, Pakistan spends only 0.08 percent on the health of its total GDP, which is the very scant amount. The study suggests that the government should make the healthcare system a priority and must increase the health budget.

The study of infectious diseases like COVID-19 was once part of only the medical domain. However, Pirages first established its relationship with state security, politics, and foreign policy in the mid-1990s (Pirages, 1995). Many historians have attempted to determine the political impacts of diseases, particularly their consequences for regime stability and the fall of governments. Watts has done an extensive study to examine the outcome of Bubonic plague on the economic and political power of Venice (Watts \& Kennedy, 1999). Besides, the dearth of state resources to combat such infectious diseases increases polarisation in already politically divided and fragile societies on the one hand. While it also shakes the legitimacy of governing elites and trust between government and masses. Thus, governments are increasingly 
at risk of facing political instability and anti-government protests. Such a scenario proves to be lethal for a politically-fragile society (Price-Smith, 2002). Although there is a comprehensive data available on infectious diseases and their likely impacts, such studies are very few which specifically discusses the case of any developing nation in terms of measuring the pandemic's impacts on its political economy. Very limited literature was found to analyze the politicoeconomic implications of COVID-19 for Pakistan. Hence, the present study is an effort to bridge this gap by discussing the on-going pandemic's impacts on Pakistan's political economy. It will be open new avenues and dimensions for future researchers as well.

\section{Data and Methodology}

The present study is descriptive and explanatory as it is an investigation of COVID-19's potential impact on the political and economic life of Pakistan. Cause and effect relations have been explained by adopting a mixed-method research design as it involves the quantitative and qualitative interpretation of the data simultaneously. As the only application of either quantitative or qualitative research design was not appropriate and enough to develop a better understanding of the problem investigated in the study. It uses the numerical data of health facilities available in Pakistan at different tiers of administrative level, like union council, district, and division levels. A comparison is made with the available health facilities with the population of the area. Besides the quality of health infrastructure, modern equipment, and other critical aspects were also analyzed to examine the government's preparedness to meet the challenges of COVID-19. At the economic level, the impact of poor health infrastructure has brim implications for the economy as well. Through the analysis of health facilities data, it is deduced that in this critical scenario, huge budgetary diversions towards the health department is critical, but the economic conditions of the country could hardly manage this. Hence, the simultaneous application of both the numerical and opinion-based data provided a comprehensive framework to reach the logical findings. The study is deductive as it analyses a case study based on the broadly recognized scholarly insights that COVID-19 will grimly hit the politico-economic life of the countries. Both primary and secondary sources of research were utilized for data collection, such as; reports published by the World Health Organization, Asian Development Bank and ministry of health of Pakistan, newspaper articles, state officials' statements and briefings, journal articles, and internet sources.

\section{Discussion and Findings}

COVID-19 pandemic has brought the world economies close to a global recession. As the measures meant to counter the spread of the virus, mainly lockdown has restricted mobility to maintain social distancing, but due to such actions, shortage of supply has been faced domestically (Mahar, 2020). Besides, restrictions on imports have slowed down economic activities. Likewise, the Pakistani economy has to face a considerable setback due to the imposition of smart and complete lockdown. The impact of COVID-19 on the politicoeconomic life of Pakistan can be bifurcated into two sections; the first section attempts to analyze the economic impacts under two parts, part one deals with the exogenous factors, and the latter describes the endogenous forces. The second section copes with political impacts and is endeavoured to integrate economic impacts with politics.

\subsection{Economic Implications}

Though Pakistan may not have a larger share in the Global Value Chain (GVC) yet, the country 
may not be immune to the impacts of international lockdown due to having substantial integration with the international market. Among the five major trade partners (China, UK, USA, Japan, and Germany) of Pakistan, four are on the worst hit by COVID-19.; their imports and exports have significantly been reduced in the last four months (Hussain, 2020). Such significant trade disruption of these partner countries has created a very worrying situation for Pakistan as the USA and China are the major import partners for the import of capital and semifinished goods. Though $32 \%$ of the total imports are in the form of final goods and the reduction in this category would not significantly affect annual GDP. However, the remaining 68 percent, which constitutes the raw material, intermediate goods, and capital goods, used to produce final goods that are either consumed at the domestic level or exported to other countries (Sareen, 2020). A decline in this category will, consequently, severely harm investment spending on the one hand and exports on the other.

Similarly, being Pakistan's major export partner, any economic fall-out faced by these economies would directly influence Pakistan's exports and, ultimately, GDP. In addition, the impact of internal lockdown may lead to substantial tail off in Foreign Direct Investment (FDI) and remittances, and disrupt other sectors like aviation, tourism, and hospitality etc. Foreign remittances constitute a significant chunk of GDP as Pakistan is counted among the top ten recipients of international remittances. In Financial Year 2019, \$21.8 billion foreign remittances were received from overseas Pakistanis mainly working in Gulf Cooperation Council (GCC) countries, North America, and Europe. In addition to this amount that was sent by using formal channels, approximately 40 percent remittances are sent through informal channels such as; hand-carry, hawala hundi etc., (Salik, 2020). Nearly 625,203 Pakistanis went abroad in 2019 (according to BEOE data); hence, there was an expectation of receiving more remittances in the coming months. Remittances received during the first half of the financial year 2019-20 accounted for about half (49.15 percent) of the countries, import receipts and counterbalanced almost the country's entire trade deficit. Another significant benefit of remittances to Pakistan pertains to their generally counter-cyclical nature. When the economy reels due to the higher prices of the imported oil, the increasing remittances keep the damage in check to a certain extent. The on-going COVID-19 pandemic has endangered this stabilizing role of the remittances.

The whole world's economy has come to a standstill during this pandemic. The aviation industry has been halted; industries and factories have been shut down; investments have been delayed; new hiring and recruitment have been ceased. The phantom of a global recession seems to appear soon. In addition to life loss and economy from COVID-19, the oil-price conflict between Saudi Arabia and Russia has seen oil prices dropped to below the US \$30 per barrel (Rehman, 2020). That has severely dented the single resource economies of the GCC countries from where Pakistan has to receive e a large chunk of remittances. However, the fusion of the above-stated twin shocks probably may decrease the volume of remittance inflows to Pakistan. In case the global economic slow-down lengthens, Pakistanis working in there will start losing employments, particularly those who are working in the construction and services sectors. The Bureau of Emigration and Overseas Employment (BEOE) data shows the bifurcation of employment types (that almost entirely comprises placement of overseas Pakistanis in the GCC countries).

The professions given in figure-1 are very much vulnerable by either medium-term or longterm lockdown. Even just a paucity of a few billion dollars' remittances may severely disturb the delicate balance in foreign payments Pakistan has recently managed. 
Figure 1: Bifurcation of Employment Type of Overseas Workers

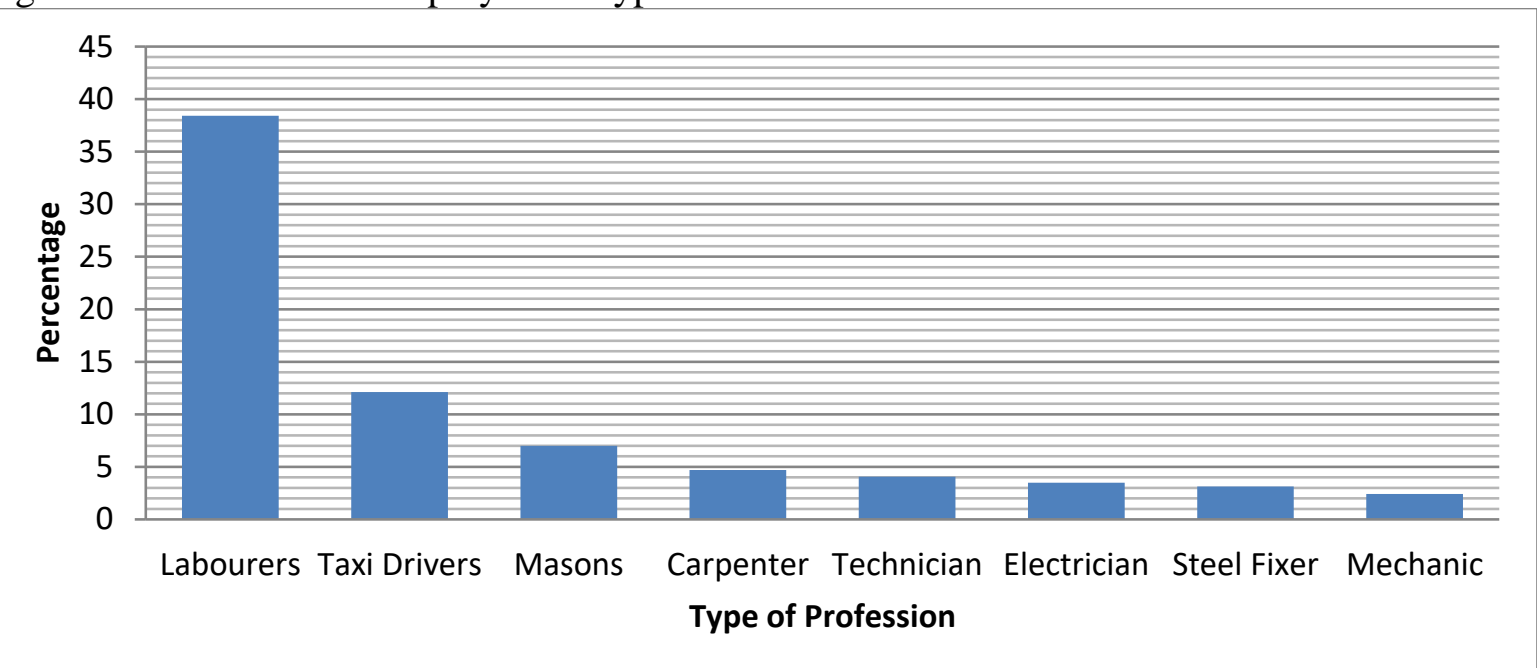

Source: Bureau of Emigration and Overseas Employment

Another major setback may be faced in the form of rising poverty levels across the country, impacting primarily those who are 'vulnerably employed', that account for about $56 \%$ of the total employment (Shah, 2020). In the worst situation, it is feared that poverty level may increase up to 125 million people. Internally, the closure of schools, colleges, universities, offices, restaurants, factories, markets and shopping malls will gravely damage the small and medium businesses that may eventually lead to mass bankruptcies. Since the middle and lowerincome groups strive to attain good income to feed themselves and to pay for necessities, which may result in hyperinflation, joblessness and total collapse of the already ventilator economy. According to the PIDE report, millions of jobs will be lost, particularly of semi-skilled and daily wagers, and approximately $2.4 \%$ of the Annual GDP will be lost because of COVID-19, which has very much potential to shift Pakistan into a spiralling recession (Salik, 2020).

\subsection{Political Implications}

The COVID-19 pandemic is also testing the political leadership of the world, as the political effects of the coronavirus could be as substantial as the economic effects. Some are emerging as strong and unifying leaders, while others flounder, particularly in such countries where public's trust in institutions is scanty. Decisive leadership has proven crucial for implementing lockdown policies and prompt provision to social assistance in the shape of different relief packages. Like Singapore, South Korea, Hong Kong, and New Zealand, leadership remained firm in implementing lockdown and became successful in curbing COVID-19. It is a fact that a dilapidated health infrastructure, limited access to health facilities, the dearth of trained health workers, and ineffective response to the disease proves to be disastrous for the political stability and the leaders' legitimacy.

However, Pakistan's Prime Minister stands out as a good example of a fast but less coordinated response by proposing an immediate social assistance plan. A sizeable economic relief package worth PKR. 144 million stands out for its stinginess towards the most vulnerable (Jamal, 2020). An enormous package of Rs.30 billion was given to support the construction industry. Investors were given extensive tax exemptions and relaxations about their source of income. "Naya Pakistan Housing Scheme" is going to begin a comprehensive project to employ daily wagers. These actions are stimulus to bring the economy back on track from a standstill position. In 
addition, about 10 million most impoverished families severely affected by lockdown are given Rs.12000 each. The Prime Minister announced a volunteer force named "Tiger Force" to ensure the immediate supply of the necessities to the most affected regions. A national relief fund has been set up to manage the extra expenses that are being incurred to fight the COVID19 impacts. Another initiative was taken by the government to bring back stranded overseas Pakistanis in the country. For this purpose, Pakistan International Airlines (PIA) issued a schedule for special international flights to bring back thousands of Pakistanis marooned in different countries due to this pandemic. Relief packages were also given to many industries. The State Bank of Pakistan was instructed to decrease the interest rate accordingly. After increasing the interest rate to $13.25 \%$ for the financial year 2020, the central bank decreased it in two stages; firstly to $11.00 \%$ in March 2020 due to the shortfall in global oil prices and very less demand in lockdown. Inflation is predicted to slow down to $8.3 \%$ in the fiscal year 2021, with the state bank expected to take further policy measures to handle inflation and boost economic activities as well (Institute of Policy Studies, 2020).

Despite all such efforts, the Pakistani government has not been able to give an adequate and coordinated response to the COVID-19 pandemic as it lacks a comprehensive strategy in combating the situation. Such a strategy includes not only medical preparedness but also a consensus among all political forces, federation, and federating units. This lack of coordination among all the federating units and federal government, along with the inadequate resources, is signalling to the lethal direction. Pakistan does not retain inexhaustible resources. Sindh government became the pioneer to impose a fourteen-day lockdown. The federal government and the other provincial governments announced partial lockdown earlier and complete lockdown later. Nevertheless, the proper management of the available resources is the need of the hour. Although, it is delusive to believe that government can tackle the infectious disease effectively and successfully with scarce resources. The political consequences of such failure may shake the already weak democratic structure. This kind of situation can best be described as Claus Offe calls it "it is not the crisis management; rather, it is "crises of crisis management" (Offe, 1976). Every province is dealing with the situation with a different strategy, which reflects the lack of national-level coordination among all provinces.

Although health is a provincial subject after the incorporation of the 18th constitutional amendment, the chaotic approach of the federal as well as provincial governments, so far, has further complicated the issue (Jamal, 2020). It has resulted in a blame-game among the centre and provincial governments. This situation does have some long-term effects on the development and strengthening of the democratic system in Pakistan. In a state like Pakistan, where democratic tradition does not provide a cheerful history, where government-opposition relations have always stand on extreme political animosity. Democratic traditions cannot be strengthened without creating harmony among political forces. Unfortunately, the COVID-19 situation seems to be further widening the cleavage among the government and opposition benches. The political leadership might avail a short-term political benefit of the situation, but the ultimate result may be fatal for democracy in the end as the Pakistan Tehreek-e-Insaf government may face a decline in the next polls, scheduled to be held in 2023.

\section{Conclusion}

Political leadership and countries' economy are at greater stake in this challenging period of COVID-19, probably the most strenuous challenge faced ever. The federal government of Pakistan and all the provincial governments aim to rescue the system through immediate 
actions and by providing relief packages, but the efforts have been proven insufficient. Hence it is pertinent to enhance the capacity of the whole of the system in one way or the other. There is a dire need to strengthen the health sector leading to more soft skills and infrastructures to capacitate health units across the country. The health budget should be increased with a significant rise. In the present situation, though priority should be to rescue people first and the economy second, but it is also needed to have a coordinated response to balance the whole system. As COVID-19 has not exposed the frail health system and myopic policy planning alone but has unravelled weak coordination among state officials at both federal as well as at provincial level. As it was observed that, the national and provincial leadership remained divided about the scale and aftermaths of lockdown. Federal government's inability to take all political forces on board may gradually increase anti-government activities and agitations. The current scenario of the pandemic might have evaded some threats to the government that was looming large a few months ago when anti-government religious and political parties were preparing for the long march or other forms of protests for mid-term elections. However, the government requires a comprehensive and harmonious response to tackle the situation efficiently. Which otherwise seems to be aggravating the response and movement of the opposition against the government once the pandemic situation gets resolved.

\section{References}

Ahmad, T., Haroon, H., Baig, M., \& Hui, J. (2020). Coronavirus Disease 2019 (COVID-19): Pandemic and Economic Impact. Pakistan Journal of Medical Sciences, 36(COVID19-S4), S73. https://doi.org.10.12669/pjms.36.COVID19-S4.2638

Armelagos, G. J., Brown, P. J., \& Turner, B. (2005). Evolutionary, historical and political economic perspectives on health and disease. Social Science \& Medicine, 61(4), 755765.

Bloom, D. E., \& Cadarette, D. (2019). Infectious disease threats in the twenty-first century: strengthening the global response. Frontiers in immunology, 10, 549. https://www.frontiersin.org/articles/10.3389/fimmu.2019.00549/full

Institute of Policy Studies. (2020, April 13). COVID-19: - Economic Impact of Coronavirus on Pakistan. http://www.ips.org.pk/covid-19-global-challenge-national-responseeconomic-impact-of-covid-19-on-pakistan-1st-session/.

Guillen, M. (2020, June 4). The Politics of Pandemics: Why Some Countries Respond Better Than

Others.

https://knowledge.wharton.upenn.edu:https://knowledge.wharton.upenn.edu/article/ politics-pandemics-countries-respond-better-others/

Hussain, A. (2020). What Do Confirmed Numbers Tell Us? Using an Adapted Seir Model for Estimation of COVID-19 in Pakistan. PIDE Covid-19 E-Book, 49-54. https://www.pide.org.pk/pdf/SEIR-Model-for-Pakistan.pdf

Janjua, R. W., Chandio, K., Khan, U. F., \& Nizamani, U. (2020). Post-COVID-19 World and Pakistan's Response Strategy. Journal of Current Affairs, 4(1\&2), 29-50. https://ipripak.org/wp-content/uploads/2020/08/Article-2-Raashid-W-Janjua-et-alJoCA-4-1 and2-ED-SSA.pdf

Jamal, U. (2020, April 15). Amid COVID-19, A Governance Crisis Looms in Pakistan. The Diplomate: https://thediplomat.com/2020/04/amid-covid-19-a-governance-crisislooms-in-pakistan/

Bedford, J., Enria, D., Giesecke, J., Heymann, D. L., Ihekweazu, C., Kobinger, G., ... \& Ungchusak, K. (2020). COVID-19: towards controlling of a pandemic. The Lancet, 395, 1015-1018. https://doi.org/10.1016/S0140-6736(20)30673-5 
Mahar, I. (2020). Impact of Covid-19 on Global Economy Structure. Modern Diplomacy. https://moderndiplomacy.eu/2020/04/22/impact-of-covid-19-on-global-economystructure/

Malani, A., \& Laxminarayan, R. (2011). Incentives for reporting infectious disease outbreaks. Journal of Human Resources, 46(1), 176-202. http://jhr.uwpress.org/content/46/1/176.short

Noreen, N., Dil, S., Niazi, S. U. K., Naveed, I., Khan, N. U., Khan, F. K., ... \& Kumar, D. (2020). Coronavirus disease (COVID-19) Pandemic and Pakistan; Limitations and Gaps. Global Biosecurity, 1(3).

Offe, C. (1976). Crisis of Crisis Management: Elements of a Political Crisis Theory. International Journal of Politics, 6(3), 29-67.

WHO. (2020). Coronavirus disease 2019 (COVID-19) Situation Report - 72. https://www.who.int/docs/default-source/coronaviruse/situation-reports/20200401sitrep-72-covid-19.pdf.

Patrick, S. (2011). Weak Links: Fragile States, Global Threats and International. New York: Oxford University Press.

Pirages, D. (1995). Microsecurity: Disease organisms and human well-being. Washington Quarterly, 18(4), https://www.tandfonline.com/doi/abs/10.1080/01636609509550167

Price-Smith, A. T. (2002). The health of nations. Infectious Disease, Environmental Change and Their Effects on National Security and Development.

Rehman, F. (2020, June 9). Covid-19 and Impact on Economy. The Express Tribune. http://tribune.com.pk/story/2202021/2-covid-19-impact-economy

Salik, M. A. (2020, May 02). Impact of Covid-19 on Economy of Pakistan. Institute of Strategic Studies, 1-3. http://issi.org.pk/wpcontent/uploads/2020/05/IB_Ahamd_Salik_May_2_2020.pdf

Samal, J. (2014). A Historical Exploration of Pandemics of Some Selected Diseases in the World. nternational Journal of Health Sciences and Research, 4(2), 165-169. https://www.ijhsr.org/IJHSR_Vol.4_Issue.2_Feb2014/IJHSR_Abstract.026.html

Sareen, S. (2020). COVID19 and Pakistan: The Economic Fallout. Mumbai: Observer Research Foundation.

Shafi, M., Liu, J., \& Ren, W. (2020). Impact of COVID-19 pandemic on micro, small, and medium-sized Enterprises operating in Pakistan. Research in Globalization, 2. https://doi.org/10.1016/j.resglo.2020.100018

Shah, S. K. (2020, April 27). COVID-19 Impact: What we know so far - Pakistan. (I. P. Federation, Interviewer)

Watts, A. M., \& Kennedy, R. C. (1999). DNA vaccination strategies against infectious diseases. International journal for parasitology,29(8), 1149-1163. https://www.sciencedirect.com/science/article/abs/pii/S0020751999001125?via\%3 $\underline{\text { Dihub }}$

Worldometer. (2020). COVID-19 Coronavirus

Pandemic. https://www.worldometers.info/coronavirus/

Wu, Y. C., Chen, C. S., \& Chan, Y. J. (2020). The outbreak of COVID-19: An overview. Journal of the Chinese Medical Association, 83(3), 217. http://doi.org.10.1097/JCMA.0000000000000270 